\title{
Bordado de mnemosine: romance e memória em Lídia Jorge
}

\author{
Mauro Dunder ${ }^{1}$
}

\begin{abstract}
Pois memória e profundidade são o mesmo, ou antes, a profundidade não pode ser alcançada pelo homem a não ser através da recordação.
\end{abstract}

Hannah Arendt

Mircea Eliade, em Mito e realidade, afirma que a deusa Mnemósine "é a personificação da "Memória", irmã de Cronos e de Oceanos, é a mãe das Musas. Ela é onisciente: segundo Hesíodo (TEOgonia, 32, 38), ela sabe 'tudo o que foi, tudo o que é, tudo o que será" (Eliade, 2011, p. 108). Assim, essa figura mitológica está intrinsecamente relacionada com a ideia de História, a ciência que, a fim de compreender o presente e preparar o futuro, escava as ruínas do passado, em busca de ambos, inspiração e informação. Entretanto, uma das conquistas da contemporaneidade é a noção de que, assim como qualquer forma de conhecimento narrado, a História é condenada a uma visão sempre parcial dos eventos: o que ela dá a conhecer é, de fato, uma História, a que Marilena Chauí se refere como "a história oficial celebrativa cujo triunfalismo é a vitória do vencedor a pisar a tradição dos vencidos” (CHAUí, 2O12, p. 17).

No universo da literatura, o século passado assistiu ao surgimento de uma nova perspectiva para a relação entre História e escrita. Enquanto o século XIX deu vida ao que se configurou e sedimentou como "romance histórico", o século xx viu nascer o conceito de metaficção historiográfica, cuja base está no mesmo reconhecimento conquistado pela História: "Os livros de história [...] são também um ponto de vista, uma versão do acontecido, não raro desmentidos por outros livros com outros pontos de vista" (BosI, 2012, p. 37).

Segundo a teoria de Georg Lukács, o romance é a forma literária mais afeita aos movimentos políticos e econômicos da sociedade burguesa, cuja plasticidade de valores e ações e grau de transformação (especialmente perante uma concepção estática de mundo, herdada da antiguidade clássica e adaptada à vida europeia ao longo dos séculos seguintes), em várias esferas, trouxe aos

Doutor em Letras (Literatura Portuguesa) e professor da Universidade Federal do Rio Grande do Norte (UfRN), Natal, Rio Grande do Norte, Brasil. E-mail: dunder@usp.br 
séculos XVIII e XIX uma desconstrução importante, no tocante às identidades individuais e nacionais (LUKÁcs, 2000).

Em grande medida, confirmando a concepção lukacsiana, o gênero romanesco adaptou-se também ao rol de mudanças de contorno geopolíticos, econômicos e sociais do século xx. Se há ou não crise do gênero na contemporaneidade, não cabe aqui discutir, embora seja possível dizer que a ideia de crise, como momento de desconstrução e revisão de valores, esteja, por assim dizer, na própria natureza do romance, como fruto de uma sociedade cujos valores estiveram, a rigor, em profundo movimento de crise.

Se, ao longo do século XIX, a literatura dará lugares a distintas perspectivas a respeito da dinâmica social - são provas disso o Romantismo português, especialmente o de Júlio Dinis, e o Naturalismo francês, como o de Émile Zola -, não será diferente com o século xx, tributário direto do fenômeno da Modernidade, da qual o romance, por sua natureza maleável como forma, será o gênero de eleição. $\mathrm{Na}$ esteira desse pensamento, sobre o conceito de identidades culturais na modernidade, Boaventura de Sousa Santos afirma que "não são rígidas, nem, muito menos, imutáveis", mas, antes, são resultados de uma "sucessão de configurações hermenêuticas que de época para época dão corpo e vida a tais identidades. Identidades são, pois, identificações em curso". Afirma, ainda, que é, "pois, crucial conhecer quem pergunta pela identidade, em que condições, contra quem, com que propósitos e com que resultados" (SANTOS, 2002, p. 119).

Além de toda a instabilidade trazida pela Modernidade em seu bojo, Portugal viveu, entre 1901 e 2000, uma série de eventos determinantes não apenas de seu rumo como nação, como também de uma questão com que se debate desde sua fundação como Reino, no século XII, qual seja a da percepção dos contornos de sua identidade: as consequências do ultimatum inglês; os eventos brutais que levaram à queda da Monarquia; o início conturbadíssimo do período Republicano; a instauração de um regime militar; a ascensão de Salazar, misto de Dom Sebastião e Torquemada que dirigiu os destinos do país por quase quarenta anos; a luta desenfreada para manter a condição anacrônica de império colonial; uma revolução ambígua, a qual, ao mesmo tempo que mudou os destinos da nação, relutou em abrir mão das províncias ultramarinas e reconhecer a violência dessa situação; a busca pelo caminho que Portugal trilharia, após abril de 1974; a luta contra o complexo de 
inferioridade que há séculos caracteriza a relação do país com sua condição de nação europeia.

Essa série de eventos, especialmente os ocorridos a partir de 1932, acabaram por fornecer à literatura portuguesa, especialmente ao romance, um apanágio para discussões acerca da identidade portuguesa, em sua constituição mais íntima e, ao mesmo tempo, coletiva. Pelas mais diversas razões, a literatura de Portugal constitui artefato importantíssimo para compreender o pensamento de seu povo, em que pese a já mencionada relatividade de todo ponto de vista, ainda mais o que se consubstancia em narrativa de ficção.

Nesse panorama, a tela bordada por Lídia Jorge, ao longo de seus, até agora, onze romances, constitui uma das muitas representações possíveis do Portugal "que foi" e do "que é", apontando, consequentemente, para uma imagem do Portugal "que será". Desde 1980, quando publicou $O$ dia dos prodígios, a escritora do Algarve faz de sua escrita instrumento de reflexão sobre seu tempo, sem nunca tirar os olhos do passado que o formara e sem perder de vista as possibilidades de como a sociedade lusitana terá de lidar com o que a espera. Nesse sentido, romances como Os memoráveis (2014) exercem o fundamental papel de trazer para a contemporaneidade os reflexos das situações vividas na esteira da Revolução dos Cravos, em uma espécie de retorno à temática de $O$ dia dos prodígios e $O$ cais das merendas (1982).

Sob diferentes perspectivas, as noções de História e sociedade no conjunto dos romances de Lídia Jorge são dadas a conhecer por meio de uma teia de vozes que, via de regra, em uma espécie de discurso polifônico, não são os interlocutores cuja fala constitui a versão oficial da História, dando a ver novas versões dos fatos, pela perspectiva de quem, no âmbito da representação ficcional, viveu-os ou os viu de perto. É a voz dos excluídos, vocalizada pela narrativa da escritora do Algarve.

Nessa perspectiva, os onze romances de Lídia Jorge constituem um panorama de construção de memória social, no sentido de que o resgate de eventos e fatos históricos, representados pela narrativa, dão a conhecer traços importantes do pensamento português, não apenas em sua face contemporânea, mas ensejando a possibilidade de compreender o movimento ideológico que a configura. Afinal,

como dissera Benjamin, [...] o porvir não é um ponto objetivo previsível, nem o tempo, uma linha homogênea e vazia [...]. [Sobre a substância social da memória] o modo de lembrar é individual tanto quanto social: o grupo transmite, retém e 
reforça as lembranças, mas o recordador, ao trabalhá-las, vai paulatinamente individualizando a memória comunitária e, no que lembra e no como lembra, faz com que fique o que signifique. O tempo da memória é social (CHAuí, 2012, p.31).

Assim, é falsa a noção de que a autora escreva livros de cunho unicamente histórico e social. Suas narrativas, tais quais telas bordadas, que juntas constituem um quadro maior, podem - e devem - ser lidas em, pelo menos, duas dimensões, já que as personagens mais relevantes de sua obra romanesca são, ao mesmo tempo, objeto e atores dos eventos históricos da sociedade portuguesa.

Mais do que isso, são indivíduos cujas trajetórias compõem o quadro social lusitano. Por meio de romances ambientados em aldeias do Algarve e em Lisboa - exceção feita a $A$ costa dos murmúrios, que se passa em Moçambique -, Lídia Jorge enriquece a leitura da História de Portugal com múltiplos pontos de vista. Convivem no quadro maior os alienados habitantes de Vilamaninhos, presos em sua vida medieval; os da Redonda, desejosos de apagar qualquer traço de lusitanidade de seus cotidianos, em tentativa infrutífera de não serem quem são; lisboetas desorientados com relação ao país que, após a Revolução dos Cravos, ainda não mostrou aonde vai; militares anacrônicos, cuja luta de vida é manter, na África, um império que já se esfacelou.

Somam-se a eles jovens que, alheios à própria História recente do país, vivem em função de projetos individuais - e individualistas - de fama e fortuna; fazendeiros e proprietários de terras que não têm o discernimento para compreender as mudanças que os cercam; mulheres poderosas, não pelos atos masculinizados, mas por deterem a sensibilidade e as palavras para verem além do que se faz visível; fantasmas de tempos imemoriais e de tempos recentes, que fazem de Portugal a nação que, apesar de não querer ser, é.

Nesse sentido, Henri Bergson, em Matéria e memória, ao discutir as relações entre o que ele chama de percepções (signos que denotam a concretude do presente) e as lembranças, indaga:

Elas [as "percepções ausentes da consciência"] não se criam à medida que a consciência as acolhe; elas lá estavam já, de algum modo; ora, como, por hipótese, a sua consciência não as apreendia, como podiam existir em si senão no estado inconsciente? De onde vem, então, que uma existência fora da consciência nos pareça clara quando se trata de objetos, mas obscura quando falamos de sujeitos? (BERGSON, 2010, p. 167). 
Merecedor de um olhar mais detido a esse respeito, José Jorge Júnior, personagem de $O$ dia dos prodígios, dá vida, no âmbito da trama do romance, às ideias a que Bergson se refere com "percepções ausentes da consciência" e "existência fora da consciência", as quais, por sua vez, estão intimamente ligadas aos signos que, a partir dessas percepções, despertam as relações com a memória. Trata-se de uma experiência avassaladora, em que os signos da memória sobrepõem-se à "percepção pura", como se percebe no trecho que segue:

- Chega-te aqui Esperancinha, senta-te nesta cadeira e tira o lenço da cabeça para ouvires o que ainda me lembro sobre a gente dos meus passados. Oh Esperancinha. $\mathrm{O}$ avô do avô desse meu avô, que comigo andou ao colo, nasceu das ervinhas. Encontraram-no dentro dum balaio como se fosse uma mão cheia de figos para dar aos porcos. Ali no Vale Murtal no meio das marioilas e dos troviscos. Uma velha muito velha, mais velha que saragoça, oh Esperancinha. Ia andando curvada, pedrinha aqui, pedrinha ali, e vai e dá com aquilo com um dia de parido, todo cheio de formigas e a roer os dedos [...].

José Jorge Júnior sabe que sua mulher pode não o ouvir, mas sempre o escuta. E por isso chega-se mais junto dela, arrastando o banco para aí se empoleirar de novo [...].

- A velha ao tempo já era bisavô de uma porção de bisnetos, oh Esperancinha. Mas tinha uma cabra com tetas do tamanho de pipas. Vai daí, pensou a velha que esse seria o último sacrifício da vida, e que assim, São Luís a alimparia de um resto de ofensas feitas em vida. Trouxe-o para casa, deu-lhe leite da cabra, papa de milho, umas colheres de batata doce, e não é que o raio desse meio avô começou a crescer e a medrar como se mamasse da mãe? [...]

- Tu bem sabes, Esperancinha, que antes dos meus avós isto aqui era um deserto. Só havia na curva do rio um moinho velho, onde de noite, apareciam medos. Neste sítio em que tudo prantas o pé, era mato alto, como nesse tempo havia, com lenha até à cabeça de um homem (JoRGE, 1995, p. 28-31).

No contexto da trama de $O$ dia dos prodígios, a fala de José Jorge Júnior, sob a perspectiva da memória, como a concebe Bergson, remete diretamente à relação entre a percepção do presente e a memória, evocada por signos deste presente que trazem à tona as lembranças represadas no inconsciente da personagem. Vilamaninhos, o vilarejo em que se dá a narrativa, constitui exemplar do atraso em que o interior de Portugal - neste caso, a região do Algarve - vivia ainda nos estertores do período salazarista; assim, a evocação da memória da personagem, mais do que recuperar signos do inconsciente, 
relaciona-se intimamente com a percepção do presente: o vilarejo continua sendo quase tudo o que as lembranças do idoso conservaram, constituindo um grau elevado de incômoda (para o leitor) aproximação entre os dois aqui em discussão - a percepção pura e a memória.

$\mathrm{Na}$ esteira desse pensamento, é relevante perceber, também, que o relato de José Jorge Júnior ganha significado no âmbito da memória social, como a concebe Halbwachs: a proximidade entre os planos da percepção e da memória denota, inequivocamente, que o segundo é fruto de uma composição coletiva, fruto de processo socioeconômico e político, o que aponta para uma constatação ainda mais incômoda, qual seja a da quase ausência de transformações nessas esferas.

Walter Benjamin, ao discutir a questão do resgate das experiências em narrativas que, afinal, se configuram como de memória, estabelece duas imagens reveladoras para duas naturezas relativamente distintas de vozes narrativas. Nas palavras do filósofo,

A figura do narrador só se torna plenamente tangível se temos presentes esses dois grupos. "Quem viaja tem muito que contar", diz o povo, e com isso imagina o narrador como alguém que vem de longe. Mas também escutamos com prazer o homem que ganhou honestamente sua vida sem sair do seu país e que conhece suas histórias e tradições. Se quisermos concretizar esses dois grupos através dos seus representantes arcaicos, podemos dizer que um é exemplificado pelo camponês sedentário, e outro pelo marinheiro comerciante (BENJAMIN, 1996, p. 197-198).

Donos de saberes que se interpenetram, figuras que remetem ao trabalho nas oficinas da Idade Média, o camponês e o marinheiro estabelecem, assim, duas formas de memória, de igual prestígio, mas de diferentes naturezas: enquanto um fornece os registros do que se viveu na terra em que se encontra, representativos de um modo de vida e de uma concepção de mundo, o outro traz, por meio dos relatos de sua experiência, não apenas um leque de representações distintas, mas, a rigor, os espelhos distorcidos que, ao mesmo tempo em que darão a medida da diferença entre uma vivência e outra, tornam mais pleno de sentido um presente comum a ambos. Nesse sentido, a obra de Lídia Jorge apresenta, ao longo dos onze romances até agora publicados, uma série de camponeses e marinheiros, não apenas no sentido literal das expressões, mas, principalmente, na concepção metafórica que lhes atribui o texto de Benjamin. 
Assim, a memória de José Jorge Júnior, além de particularização da memória de uma parcela do povo português, é a marca da estagnação de Portugal, além de, como se percebe, sugerir fortemente que, na identidade dessa nação, memória e percepção confundem-se como traço constitutivo, uma vez que perceber e lembrar resultam, com pouquíssimas distinções, em uma relação de sinonímia, ainda que, por definição, imperfeita. Na esteira do pensamento de Walter Benjamin, a narrativa de memória de José Jorge Júnior constitui, como fonte de elementos para compreender o presente, a riqueza da cultura tecida ao longo de anos de sedentarismo - geográfico, econômico, social, cultural.

Por extensão, é possível constatar que as narrativas de Lídia Jorge, como em um bordado, trançam os fios das individualidades, e todos os componentes de sua identidade, com os dos eventos coletivos, de modo que as trajetórias constituam tramas indissociáveis, atadas pelo fio composto exatamente pela relação entre as percepções do presente e a (por vezes incômoda) relação com os signos representativos da memória: a vida de Carminha Parda, de $O$ dia dos prodígios, não se separa do cotidiano de Vilamaninhos (nem as lembranças de José Jorge Júnior distanciam-se significativamente desse mesmo cotidiano), assim como a de Sebastião Guerreiro, de $O$ cais das merendas, não se distancia dos eventos da Redonda e a trajetória de Osvaldo Campos, protagonista de Combateremos a sombra (2007) não se compreende fora do entendimento de como pensa e vive Lisboa.

Note-se, sobretudo, que, apesar de localizadas temporalmente nas décadas de 70 e 80 do século xx e na virada para o século XxI, respectivamente, todas essas personagens vivem as reverberações de uma História quase milenar, carregando em si todas as marcas, conscientes ou não, do que significou, em cada momento, ser português.

Na esteira desse pensamento - e da formulação de Walter Benjamin para a questão do narrador na construção do discurso de memória -, A costa dos murmúrios (1988) talvez constitua um dos escritos romanescos mais importantes da obra de Lídia Jorge. A partir da narrativa de memória de Eva Lopo, personagem central do romance, o jornalista Álvaro Sabino reconstitui um episódio marcante da história da presença portuguesa em Moçambique, o do assassinato em massa de nativos, nunca investigado profundamente e, no âmbito do romance, testemunhado pela esposa do oficial Jorge Alex, então Evita, posteriormente Eva. 
No processo de recolha e reconstituição de passagens memorialísticas, o discurso de Álvaro Sabino, à medida que revela eventos depois retomados pela própria Eva Lopo, mostra a manipulação do discurso romanesco na tessitura da trama de memória. Sabino, jornalista nativo, dá ao leitor acesso a uma narrativa cuja trama, ainda que já anuncie a crueldade com que determinados eventos acontecem, não corresponde exatamente àquela que se constitui pela narração direta, feita pela personagem principal não apenas a partir de, mas como forma de confronto a, um ponto de vista externo ao da vivência.

Por outro lado, ainda que tenha adquirido a condição de moradora da cidade da Beira, como esposa de um oficial do exército português, o ponto de vista pelo qual se dão a ver os registros memorialísticos dessa vivência pertencem a alguém que, por natureza, naquele lugar e naquele tempo, constituiriam o olhar do viajante a que se refere Benjamin, o que se percebe no trecho a seguir:

Esse é um relato encantador. Li-o com cuidado e concluí que nele tudo é exacto e verdadeiro, sobretudo em matéria de cheiro e de som - disse Eva Lopo. Para o escrever desse modo, deve ter feito uma viagem trabalhosa a um tempo onde qualquer outro teria dificuldade em regressar. [...] Além disso, o que pretendeu clarificar clarifica, e o que pretendeu esconder ficou imerso.

Imerso, claro, o que não poderia ser doutro modo. O sentido da sua recordação, atendendo ao que se recorda, mantém-se tão inviolado quanto o é, por exemplo, a razão profunda do pêssego [...]. No pêssego, como em qualquer outro corpo, tudo converge para um caroço inquebrável, que existe dentro e fora de todo o caroço, e que não se vê nem se acha na implosão dos frutos, nem na explosão deles até às coisas siderais. [...] Ora bem, não será perverso dizer a quem pretender achar o âmago dessa pequena recordação, que não o acha, mesmo que, um a um, persiga os passos de todas as figuras que patinharam nesse Verão secreto, até ao último instante. Misterioso como o pêssego - uma memória fluida é tudo o que fica de qualquer tempo, por mais intenso que tenha sido o sentimento, e só fica enquanto não se dispersa no ar. Embora, ao contrário do que se pense, não ignore a História (JORGE, 2004, p. 41-42, grifo nosso).

Ainda que, no contexto da trama de $A$ costa dos murmúrios, a menção que Eva Lopo faz a alguém que tivesse de "ter feito uma viagem trabalhosa" adquira sentido próprio (e distinto daquele de Benjamin), não deixa de chamar atenção o fato de que a narradora tenha-a usado justamente para se referir ao resgate de signos e circunstâncias ligados ao universo da memória reconstituída. Guardadas as devidas peculiaridades, a ação do jornalista Álvaro 
Sabino, aos olhos de Eva Lopo, constitui a relação formulada por Bergson entre a percepção e a lembrança: o primeiro desperta signos do segundo, os quais revestem o presente e, paradoxalmente, afastam-no da concretude da própria percepção.

Entretanto, é possível inferir que a visão manifestada por Eva Lopo, não apenas a respeito dos eventos narrados, mas também acerca da narrativa constituída pelo jornalista Sabino, a partir dos signos da memória resgatados pela própria Eva, constitua-se em amostra da visão de alguém externo ao cenário em que a ação se passa. Ao acompanhar o marido oficial do exército, a doce Evita depara-se com imagens que não correspondem ao que é conhecido por meio da História oficial, o que revela, de antemão, a condição de externa, estrangeira, viajante, cuja percepção do presente não sofre a influência, ao menos de imediato, de nenhum dos signos de lembrança. Ao contrário, é por meio do aprendizado vivido na cidade da Beira que a memória de Eva Lopo se constrói, a ponto de dotá-la da capacidade de ler a narrativa de Álvaro Sabino e compará-la ao que ela, de fato, viveu.

É uma constante no discurso romanesco de Lídia Jorge a utilização de mecanismos pelos quais os narradores de sua obra discutem não apenas eventos - em suas dimensões individuais e sociais - mas o próprio ato de escrever como ação ideológica, instituidora de um ponto de vista a respeito da História; uma percepção, na acepção de Bergson, que carrega os laços com os signos da memória emergidos do inconsciente, a qual assume relevância tão grande quanto a própria sucessão de eventos que constituem qualquer narrativa.

Para ela, escrever não é estabelecer a História na literatura, mas, ao contrário, dar voz a perspectivas sobre essa História que, via de regra, não seriam vocalizadas. É a voz dos aldeões, das viúvas pobres, dos funcionários públicos, distantes das vozes autorizadas pelos relatos históricos. A autora traz à baila a discussão sobre a natureza e o poder da palavra, como instrumento da construção da identidade de um povo; ao usar a palavra como fio de bordado, Lídia Jorge o faz de modo que o verso da tela, com as marcas dos pontos impingidos ao tecido, proporcione uma leitura tão rica e significativa quanto o anverso - narrar é, portanto, tão Histórico e ideológico quanto cada um dos eventos que são objetos dessa ação. 
Em que pese a relevância dos conceitos de Henri Bergson a respeito da categoria filosófica da memória, sob a perspectiva da psicologia social, é na teoria de Maurice Halbwachs, especialmente em A memória coletiva, que se encontram explicitadas as relações entre lembrança e perspectiva social as quais elucidam a base filosófica dos romances da autora. $\mathrm{Na}$ esteira dos estudos de Émile Durkheim, o pensamento de Halbwachs parte do pressuposto de que

as relações a serem determinadas [entre presente e memória] já não ficarão adstritas ao mundo da pessoa (relações entre o corpo e o espírito, por exemplo), mas perseguirão a realidade interpessoal das instituições sociais. A memória do indivíduo depende de seu relacionamento com a família, com a classe social, com a escola, com a Igreja, com a profissão; enfim, com os grupos de convívio e os grupos de referência peculiares a esse indivíduo (Bosı, 2012, p. 54).

Logo, os romances de Lídia Jorge revelam lados de Portugal por meio da criação de personagens complexas e da ressignificação de eventos basilares na História do país - a Revolução dos Cravos, o desenrolar do avanço político e econômico vivido pelo país, a perspectiva - ou a falta dela - para as novas gerações, dentro do panorama socioeconômico português, ainda que, no tocante à linguagem, tenha se aproximado do que se pode ver como "convencional".

Nesse sentido, torna-se crucial olhar para a maneira como a narrativa de Os memoráveis (2014) relaciona-se com a questão da História, do presente e da memória, especialmente por meio da trajetória da personagem principal: Ana Maria Machado é uma jornalista portuguesa, radicada nos Estados Unidos que, trinta anos depois da Revolução dos Cravos (1974), é instada a voltar a seu país e, por meio de uma investigação, reconstruir as entranhas de um momento crucial da História recente de Portugal.

Ao longo da obra, a visão de Ana Maria Machado sobre seu país e, especialmente, sobre o que teria sido a insurreição de abril de 1974 vai sendo construída a partir de uma fotografia - tirada em um restaurante conhecido por Memories - na qual aparecem algumas pessoas diretamente ligadas ao 25 de Abril. Ao buscar conhecer essas pessoas - reencontrar, na verdade, uma vez que muitas delas fizeram parte da infância de Ana Maria -, a jornalista começa a construir um painel das várias impressões que se fizeram nas memórias das pessoas, a fim de, em última instância, construir sua própria visão do que o país teria vivido naquele momento. 
A partir da acepção de lembrança instituída por Bergson, a fotografia que a repórter rouba ao pai e utiliza para entabular conversas com cada um dos revolucionários que dela fazem parte constitui exatamente o signo do passado que inunda o presente, bloqueando a percepção e ressignificando o momento. Para Ana Machado, entretanto, trata-se da construção de uma memória própria, a partir da recolha de outras, sobre um evento que, indiretamente, ela teria vivido. É nesse nó que está baseada a trama de Os memoráveis: no caso de um evento de magnitude nacional, a quem pertence a memória? E sobre quem agem os signos que a incorporam, os valores que esses signos simbolizam e as consequências desses acontecimentos?

Outro aspecto que chama atenção na constituição do romance como signo de memória para Portugal é a própria situação de vida de Ana Maria Machado. Expatriada nos Estados Unidos, distante da Revolução dos Cravos em, pelo menos, duas esferas - a histórica e a geográfica - , a jornalista inscreve-se no grupo dos “marinheiros", conforme designado por Benjamin.

Ao retornar ao país, a repórter empreenderá um duplo resgate, com base na reconstituição de duas memórias: à medida que busca reconstruir a significação da Revolução dos Cravos para quem dela fez parte, a repórter também busca reconstruir sua própria visão sobre seu país e seu povo - e paga o preço por ser "marinheira": não reconhece, nem nos Estados Unidos, nem em Portugal, seu lugar identitário. Dessa forma, a (re)construção de uma memória coletiva trará para Ana Maria Machado, em última instância, o reconhecimento de uma memória pessoal - e de tudo o que essa memória estabelece, em relação a sua própria nacionalidade.

Ao fim e ao cabo, duas perguntas instauram-se: quem é a escritora Lídia Jorge e o que a move a escrever? Embora se esbarre na impossibilidade, a priori, de esgotar o assunto sob qualquer perspectiva, a resposta que surge, para ambas as questões, leva à percepção de que, por meio de seu romance, Lídia Jorge exerce o papel de uma Mnemósine contemporânea: diz ela que concebeu $O$ dia dos prodígios como um romance "para não esquecer, apenas para não esquecer”.

Ao longo de sua obra, mais do que simplesmente "não esquecer", a autora desperta umas reflexões muitas vezes incômodas, mas fundamentais para construir um retrato de seu povo, de sua gente, de si mesma. Como na execução de um bordado, já oferecido ao leitor por Branca Volante, 
personagem de $O$ dia dos prodígios, o fio da memória constitui, no percurso de seus romances, um painel multifocal da História de Portugal, o qual proporciona uma reflexão, ainda em construção, sobre a construção identitária do povo português, sem, entretanto, prescindir do aspecto ontológico dessa busca.

Para Lídia Jorge, é preciso seguir bordando, para que o quadro, nunca completo, ganhe cada vez mais matizes, criando uma representação cada vez mais complexa do que é Portugal, de quem é o português hoje, com os pés no passado e os olhos em uma possibilidade de futuro.

\section{Referências}

Benjamin, Walter. O narrador: considerações sobre a obra de Nikolai Leskov. In: BenJAmin, Walter. Magia e técnica, arte e política: ensaios sobre literatura e história da cultura. São Paulo: Brasiliense, 1996.

Bergson, Henri. Matéria e memória. 4. ed. São Paulo: Martins Fontes, 2010.

Bosı, Ecléa. Memória e sociedade: lembrança de velhos. 17. ed. São Paulo: Companhia das Letras, 2012.

Chauí, Marilena. Os trabalhos da memória. In: Bosı, Ecléa. Memória e sociedade: lembrança de velhos. 17. ed. São Paulo: Companhia das Letras, 2012, p. 17-33.

Eliade, Mircea. Mito e realidade. 6. ed. São Paulo: Perspectiva, 2011. (Coleção Debates).

Jorge, Lídia. O dia dos prodígios. 7. ed. Lisboa: Dom Quixote, 1995.

Jorge, Lídia. A costa dos murmúrios. Rio de Janeiro: Record, 2004.

Jorge, Lídia. Os memoráveis. Lisboa: Dom Quixote, 2014.

LukÁcs, Georg. A teoria do romance: um ensaio histórico-filosófico sobre as grandes formas da épica. Tradução de José Marcos Mariani de Macedo. São Paulo: Duas Cidades; 34, 2000.

SAntos, Boaventura de Sousa. Modernidade, identidade e a cultura de fronteira. In: Pela mão de Alice: o social e o político na pós-modernidade. 8. ed. Porto: Afrontamento, 2002.

Recebido em 19 de fevereiro de 2017.

Aprovado em 3 de março de 2017.

\section{Resumo/Abstract/Resumen}

\section{Bordado de mnemosine: romance e memória em Lídia Jorge}

Mauro Dunder

Este artigo discutirá a configuração das representações identitárias do povo português e de suas relações com os signos representativos da memória na produção romanesca da escritora contemporânea Lídia Jorge, em uma visão geral, desde $O$ dia dos prodígios (1980) até Os memoráveis (2014). Partindo dos conceitos de romance, conforme o compreendem 
Georg Lukács e Mikhail Bakhtin, de metaficção historiográfica, de acordo com Linda Hutcheon, e da categoria filosófica de memória, sob a perspectiva da psicologia social com base nas considerações de Henri Bergson, Maurice Halbwachs e Ecléa Bosi, far-se-á um mapeamento do trabalho da romancista do Algarve, no sentido de demonstrar seu projeto ideológico, qual seja o de trazer à tona questões cruciais para o entendimento da identidade portuguesa, sob perspectivas que incorporam, via de regra, vozes que, à luz da História (especialmente daquela a que Marilena Chauí refere-se como “celebrativa”), não encontram manifestação significativa .

Palavras-chave: romance português contemporâneo, memória, identidade portuguesa, Lídia Jorge.

\section{Mnemosine's embroidery: memory and novel in Lídia Jorge}

Mauro Dunder

This article will discuss the configuration of the Portuguese identitary representations and their relations with the respective representative signs in contemporary Portuguese writer Lídia Jorge's novels, in a general view, from O dia dos prodígios (1980) to Os memoráveis (2014). Dealing with Georg Lukács' and Mikhail Bakhtin's concepts of novel, Linda Hutcheon's historiographic metafiction, and the philosophical category of memory, based on Henri Bergson's, Maurice Halbwachs', and Ecléa Bosi's considerations, this article will discuss the "blueprints" of Lídia Jorge's novels, in order to establish the basis of her ideological project, which brings up crucial questions to understand Portuguese identity. This understanding is built by incorporating voices of the usually unvoiced in official History (especially the one described by Brazilian philosopher Marilena Chauí as "festive").

Keywords: Portuguese contemporary novel, memory, Portuguese identity, Lídia Jorge.

\section{Bordado de mnemosyne: romance y memoria en Lídia Jorge}

Mauro Dunder

Este artículo discutirá las configuraciones de las representaciones de la identidad del pueblo portugués y de sus relaciones con los signos representativos de la memoria en la producción narrativa de la escritora contemporánea Lídia Jorge, en una visión general, desde El día de los prodigios (1980) hasta Los memorables (2014). Considerando el concepto de novela, como lo comprenden Georg Lukács y Mikhail Bakhtin, el de metaficción historiográfica, según Linda Hutcheon, y la categoría filosófica de memoria, desde la perspectiva de la psicología social con bases en las consideraciones de Henri Bergson, Maurice Halbwachs y Eclea Bosi; se hará una cartografía del trabajo de la novelista del Algarve, para demonstrar cuál es su proyecto ideológico: sacar a la luz cuestiones cruciales para el entendimiento de la identidad portuguesa, bajo las perspectivas que incorporan, en general, voces que, en la historia oficial (aquella que Marilena Chauí llama "celebrativa”), no encuentran una manifestación significativa.

Palabras clave: novela portuguesa contemporánea, memoria, identidad portuguesa, Lídia Jorge. 